\title{
Erratum: Submillimeter and Far-Infrared Polarimetric Observations of Magnetic Fields in Star-Forming Regions
}

\author{
Frontiers Production Office* \\ Frontiers Media SA, Lausanne, Switzerland
}

Keywords: molecular clouds, far-infrared (FIR), magnetic fields, star formation, submillimeter astronomy, polarimetry

\section{OPEN ACCESS}

Approved by:

Frontiers Editorial Office

Frontiers Media SA, Switzerland

${ }^{*}$ Correspondence:

Frontiers Production Office production.office@frontiersin.org

Specialty section

This article was submitted to Stellar and Solar Physics,

a section of the journal Frontiers in Astronomy and Space

Sciences

Received: 14 August 2019

Accepted: 15 August 2019

Published: 19 August 2019

Citation:

Frontiers Production Office (2019)

Erratum: Submillimeter and Far-Infrared Polarimetric Observations

of Magnetic Fields in Star-Forming

Regions.

Front. Astron. Space Sci. 6:58 doi: 10.3389/fspas.2019.00058

\section{An Erratum on}

Submillimeter and Far-Infrared Polarimetric Observations of Magnetic Fields in Star-Forming Regions

by Pattle, K., and Fissel, L. (2019). Front. Astron. Space Sci. 6:15. doi: 10.3389/fspas.2019.00015

Due to a production error, a copyrighted figure was used as part of Figure 4 in the original article. This figure and the corresponding part label have been removed from the article and the updated Figure 4 can be seen below.

The publisher apologizes for this error and states that this does not change the scientific conclusions of the article in any way. The original version of this article was updated on July 4th, 2019.

\section{REFERENCES}

Fissel, L. M., Ade, P. A. R., Angilè, F. E., Ashton, P., Benton, S. J., Devlin, M. J., et al. (2016). Balloon-borne submillimeter polarimetry of the Vela C molecular cloud: systematic dependence of polarization fraction on column density and local polarization-angle dispersion. Astrophys. J. 824:134. doi: 10.3847/0004-637X/824/2/134

Soler, J. D., Ade, P. A. R., Angilè, F. E., Ashton, P., Benton, S. J., Devlin, M. J., et al. (2017). The relation between the column density structures and the magnetic field orientation in the Vela C molecular complex. Astron. Astrophys. 603:A64. doi: 10.1051/0004-6361/201730608

Copyright $\odot 2019$ Frontiers Production Office. This is an open-access article distributed under the terms of the Creative Commons Attribution License (CC BY). The use, distribution or reproduction in other forums is permitted, provided the original author(s) and the copyright owner(s) are credited and that the original publication in this journal is cited, in accordance with accepted academic practice. No use, distribution or reproduction is permitted which does not comply with these terms. 
A

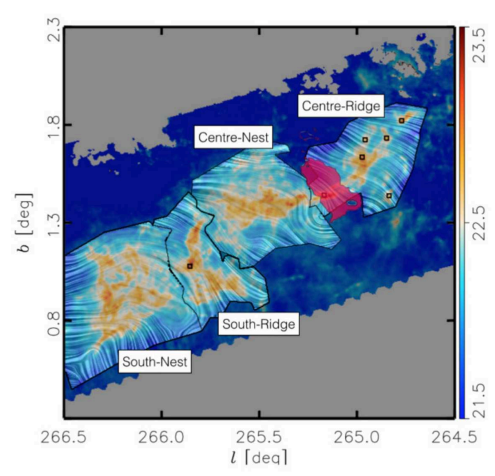

B

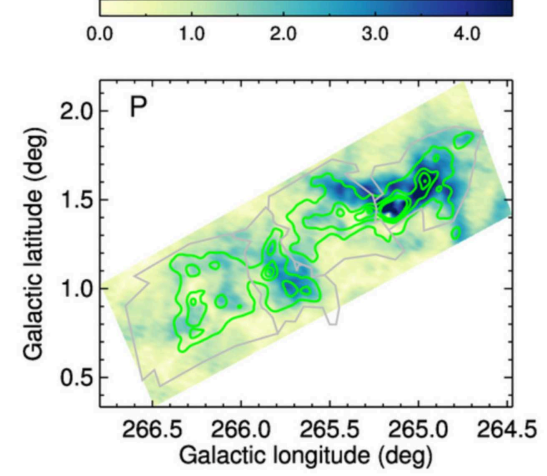

FIGURE 4 | Polarization observations of the Vela C cloud from the BLASTPol telescope. (A) Magnetic field orientation (texture) inferred from the BLASTPol $500 \mu \mathrm{m}$ data overlaid on a Herschel-derived column density $\left(N_{H}\right)$ map - Soler et al. (2017), reproduced with permission ๑ ESO. Four sub-region are labeled, while the shaded pink region indicates where the dust is heated by a compact $\mathrm{H}_{/ /}$region. (B) Map of polarized intensity with contours of total intensity (green) overlaid (from Figure 3 of Fissel et al., 2016๑ AAS. Reproduced with permission). 